\title{
PATENT COOPERATION TREATY MAY NOT BENEFIT BIOTECHNOLOGY
}

$\mathrm{T}$ he Patent Cooperation Treaty, or PCT, gives inventors the option of reserving patent protection in 32 additional countries at the same time that they file in the U.S. Thirty-three countries ratified the 1978 treaty, under which a patent filed in one country forms the basis for protection in all countries.

The inventor or company files as usual with the U.S. Patent Office but specifies that the application is under the PCT. The application must be on a standardized form, in an "agreed language" (English for U.S. applications), and must state the countries in which protection is desired. There is a fee of $\$ 65$ per country or per region. An international searching authority-typically, either the U.S. Patent Office or the European Patent Office in The Hague-then conducts an international search.

The applicant can then either abandon or go forward with the application in any of the designated countries, for up to 20 months from the date of filing in the U.S. During this period, he may also amend the application, e.g., to avoid conflicts with any preexisting patents or publications uncovered in the international search. If he wishes to proceed, the applicant must pay the national filing fees and any necessary translation fees for those countries in which he still desires patent protection.

The PCT was intended to simplify and reduce the cost of the filing and prosecution (the negotiation between patent office and patent attorney) of international patent applications. In reality, PCT fees-together with the legal fees stemming from the need to retain counsel and prosecute the application in each of the designated countries-are significantly higher than the cost of filing independently in each country.

But the benefits of using PCT procedures may outweigh the lesser costs of filing independently. A PC.T filing gives the applicant the advantage of not "filing blind"; the early search report from the international authority will normally uncover any "prior art" (the body of knowledge from which an invention must be distinguished) such as existing patents, publications, or other references that may affect patentability and dictate the withdrawal of patent applications from other countries. In addition, by affording protection for all designated countries as of the U.S. filing date and continuing for 20 months, the PCT offers companies more time to decide whether to proceed with their application in one or all of the countries involved.

Experience shows that it is this consideration that determines whether or not a company elects to use the PCT procedures. The policy of two companies, International Telephone and Telegraph (ITT) and American Standard, both major international patent holders, points to how appropriate PCT procedures might be for the biotechnology industry.

Walter Baum, ITT's international patent counsel in charge of all foreign filings, sees PCT procedures principally in cost-benefit terms. Ironically, he says, the more filings ITT abandons or the more questionable the desirability of filing, the greater the cost-effectiveness and usefulness of the PCT. Although ITT files hundreds of cases each year, only five or six of these take advantage of the PCT. If ITT abandons one out of six PCT applications, Baum finds PCT procedures not to be worthwhile; yet, if the company eliminates better than one out of four, they are. The money ITT saves on filing and legal fees by abandoning a minimum of 25 percent of its applications- whether based on the search report or ITT's own considerations-offsets the increased cost for the other 75 percent filed under the PCT. Although Baum feels his assessment is typical for the electronics industry, General Electric, he adds, reports similar findings, while Western Electric, although initially very enthusiastic about using the $\mathrm{PCT}$, is currently rethinking its position.

ITT, involved in a highly technical field, tends to know the prior art of an application. Since ITT will apply for a patent only when it is reasonably certain it both wants and will get it, the value of both the early search and the extra time afforded under the PCT is not usually relevant to its decisions.

Baum cites American Standard as a company that stands to benefit more from the PCT, as its competitors are worldwide and its field is fairly basic. Compared to ITT, the products American Standard manufactures involve a much lower degree of technical sophistication. Although voluminous quantities of patents are filed all over the world, filings in mechanical products, Standard's field, will include relatively simple mechanical drawingsa kind readily understood by lawyers and patent searchers who must uncover all prior art as part of an international search.

American Standard's reason for opting to use the PCT procedures is very specific. John Sinnott, who handles foreign filings for Standard, finds that the extra eight months available by filing under the PCT give him enough time to obtain a better evaluation of the product's commercial possibilities, which, considering that Standard's product cycle is one year, is well worth the added expense.

But what do these two examples demonstrate for the biotechnology industry? Assuredly, biotechnology companies tend to remain up-to-date with the prior art, and, like IT' $T$, they are highly sophisticated. But, as a practical matter, the complex references found in biotechnology are difficult to study and to analyze. A search is a substantial undertaking that requires a thorough reading of the specialized and highly technical materials that constitute the relevant prior art. As a result, the international searcher might overlook prior art that could lead to rejections of individual national applications, and therefore waste a company's money.

Although applying in each nation separately means a company must usually pay for filing before a search report is initiated, applying nation-by-nation might still be more cost-effective than applying under the PCT. Why? First, the PCT's early international search report on a patent in biotechnology may not be sufficiently thorough to satisfy the national patent offices. Second, a biotechnology company, knowing the prior art, is unlikely to abandon more than 25 percent of its PCT applications-the figure that both ITT and American Standard cite as the break-even point.

A biotechnology company, then, may assume that the PCT would probably not help it in filing for foreign patents. Thus, the decision to use the PCT procedures should be made only after carefully considering all of the factors, despite the advantages the PCT provides in some instances.

Jordan Bierman, Esq., is a senior partner in the New York City law firm of Bierman, Bierman \& Peroff, where he specializes in patent law. 